\title{
Weight Status and BMI-Related Traits in Adolescent Friendship Groups and Role of Sociodemographic Factors: The European IDEFICS/I.Family Cohort
}

\author{
Kirsten Mehliga Christopher Holmberg ${ }^{b, c}$ Leonie H. Bogld, e Eva Erhardt ${ }^{f}$ \\ Charalambos Hadjigeorgiou $^{g}$ Antje Hebestreit ${ }^{\text {h }}$ Jaakko Kaprio ${ }^{d, i}$ Fabio Lauria $^{j}$ \\ Nathalie Michelsk ${ }^{k}$ Iris Pigeot ${ }^{\text {h, I }}$ Lucia A. Reisch ${ }^{m}$ Toomas Veidebaum ${ }^{n}$ \\ Lauren Lissner $^{\mathrm{a}}$ On behalf of the IDEFICS and I.Family consortia

\begin{abstract}
a School of Public Health and Community Medicine, Institute of Medicine, Sahlgrenska Academy, University of

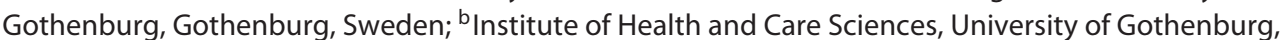

Gothenburg, Sweden; ' Department of Psychotic Disorders, Sahlgrenska University Hospital, Gothenburg, Sweden;

${ }^{\mathrm{d}}$ Department of Epidemiology, Center for Public Health, Medical University of Vienna, Vienna, Austria; Institute of Molecular Medicine FIMM, University of Helsinki, Helsinki, Finland; ' Department of Pediatrics, University of Pécs, Pécs, Hungary; ${ }^{9}$ Research and Education Institute of Child Health, Strovolos, Cyprus; ${ }^{\text {h }}$ Leibniz Institute for Prevention Research and Epidemiology, BIPS, Bremen, Germany; 'Department of Public Health, University of

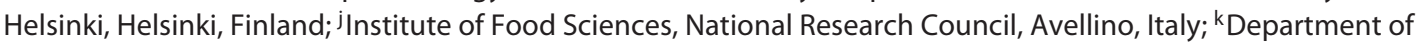
Public Health, Ghent University, Gent, Belgium; 'Faculty of Mathematics and Computer Science, University of Bremen, Bremen, Germany; ${ }^{\mathrm{m}}$ Department of Management, Society and Communication, Copenhagen Business

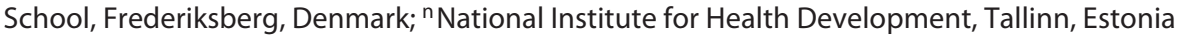

\section{Keywords}

Adolescent health · Obesity · Friendship networks · Sociodemographic factors

\begin{abstract}
Background: During adolescence, health behaviors and weight status are increasingly influenced by friendship and peer networks. This paper examines resemblances in weightrelated characteristics and how they differ by sociodemographic factors. Methods: Over 3,000 friendships were reported by 1,603 adolescents, aged 11-16 years, who participated in the school-based I.Family study in 6 European countries. Each "source child" named 1-10 friends for whom standardized weight-related traits were available in the
\end{abstract}

karger@karger.com www.karger.com/ofa

Karger $\stackrel{\text { ' }}{5}$

GOPEN ACCESS
(C) 2020 The Author(s)

Published by S. Karger AG, Basel

This article is licensed under the Creative Commons AttributionNonCommercial-NoDerivatives 4.0 International License (CC BYNC-ND) (http://www.karger.com/Services/OpenAccessLicense). Usage and distribution for commercial purposes as well as any distribution of modified material requires written permission. same survey. The mean value of the friends' traits weighted by time spent together was calculated, and related to the source child's trait. Country, age and sex of the source child, parental education, and immigrant background were considered for confounding and moderation. Results: Source children's z-scores of body fat percent and BMI were positively associated with their friends' characteristics, in particular if they had highly educated parents. Positive associations were also found regarding the frequency of fast-food consumption, impulsivity, screen time, preference for sugarsweetened foods, and hours spent in sports clubs, in increasing order of effect size. Additionally, correlations were observed between friends' cognitive and school functioning and being bullied. No associations were seen for a preference for high-fat foods, weight concerns, and health-related 
quality of life. Finally, parental education and immigrant background were associated between friends in all countries except Sweden, where no associations were observed. Conclusion: Adolescent friends shared a number of weight-related characteristics. For weight measures per se, positive associations with friends' characteristics were only observed in adolescents with high parental education. Associations regarding energy-balance behaviors and indicators of schoolrelated well-being did not differ by parental education. Parental education and immigrant background correlated positively in friends in most countries showing that social aggregation is already occurring in adolescence. The wide spectrum of friendship associations in weight-related traits and behaviors suggests that health promotion initiatives in adolescents should be directed towards peer groups in both school-related and leisure-time environments. ISRCTN Registry: Pan-European IDEFICS/I.Family children cohort (ID ISRCTN62310987; https://doi.org/10.1186/ISRCTN62310987).

$$
\begin{aligned}
& \text { (c) } 2020 \text { The Author(s) } \\
& \text { Published by S. Karger AG, Basel }
\end{aligned}
$$

\section{Background}

The influential study by Christakis and Fowler [1] was among the first to demonstrate the importance of friendship relations for weight status and risk of developing overweight and obesity in adults $[1,2]$. Friends' similarities in body weight are already observed in adolescence, a formative period with increasing peer and decreasing familial influence, and include similarities in predictors of body weight such as diet, exercise, sedentary behavior, and weight concerns [3-8]. It is not clear whether the observed similarities reflect peer influence or homophily, the latter describing the selection of friends because of existing behavioral or social similarities $[6,9]$. Similarities in health outcomes between adolescents' friends might be attributed to social networks when they are in fact explained by larger shared environments [10]. This passive selection mechanism may be particularly important for parental characteristics such as education and immigrant background, which tend to be similar in certain neighborhoods due to their correlation with income, housing costs, or school fees. Because socioeconomic conditions have large influences on health, it is important to understand whether similarities among friends are moderated by social factors. Moreover, it has been suggested that similarities between friends differ between countries, with stronger associations observed in a study of Spanish children compared to studies from the USA [11]. Anoth- er study from Germany showed a higher degree of homophily in native German children than in children from different ethnic minorities [12]. Recent immigration trends have changed the composition of schools in Europe, and children's adherence to respective migrant networks may have distinct health implications [13].

The present study has three sections. Section 1 investigates the hypothesis that associations between friends regarding body weight are already seen in adolescence, and that these associations might extend to weight-related traits and behaviors. Section 2 examines the hypothesis that correlations between friends' characteristics differ by social setting that is strata defined by parental education, immigrant status, or country. The IDEFICS.Family (I. Family) cohort study with standardized protocols across participating European survey countries is ideally suited to address this issue. Although not nationally representative, the country-specific samples provide a wide range of exposures in which the above hypotheses can be tested. Because friendship bonds tend to increase with age, including the development of sex-specific behaviors and preferences, this section also includes modification by age and sex. In a third, post hoc analysis (section 3), we tested the hypothesis that friends cluster by sociodemographic factors per se, and examined whether there are country differences in this respect. Both educational and occupational homophily have been reported for adults [9], but it is unclear how early in life this occurs.

\section{Subjects and Methods}

\section{The IDEFICS/I.Family Cohort}

The I.Family study was initiated in 2013 [14], with survey centers in 8 European countries (Belgium, Cyprus, Estonia, Germany, Hungary, Italy, Spain, and Sweden), where each center comprised 2-3 municipalities [9]. I.Family was a longitudinal follow-up of the previous IDEFICS cohort [15], with newly recruited siblings from the same families, totaling 9,639 children between the ages of 2 and 18 years. Each child in the survey had at least 1 participating parent who contributed data on the family environment. Selected municipalities were not intended to represent the respective survey country. Rather, the selection criterion was comparability regarding infrastructure and average sociodemographic characteristics such that municipalities may serve as case-control regions for a lifestyle intervention regarding childhood overweight. Children were then approached in school and kindergarten settings, which facilitated the recruitment of children and the implementation of a health-promotion intervention $[15,16]$.

Definition of Friendships and Analytic Sample

The present study is based on a subsample of 11-18 year olds participating in I.Family, who were included in an optional survey to document peer friendships within the cohort. Friends were 
Fig. 1. Definition of the analytic sample including exclusion criteria for source children and friends.

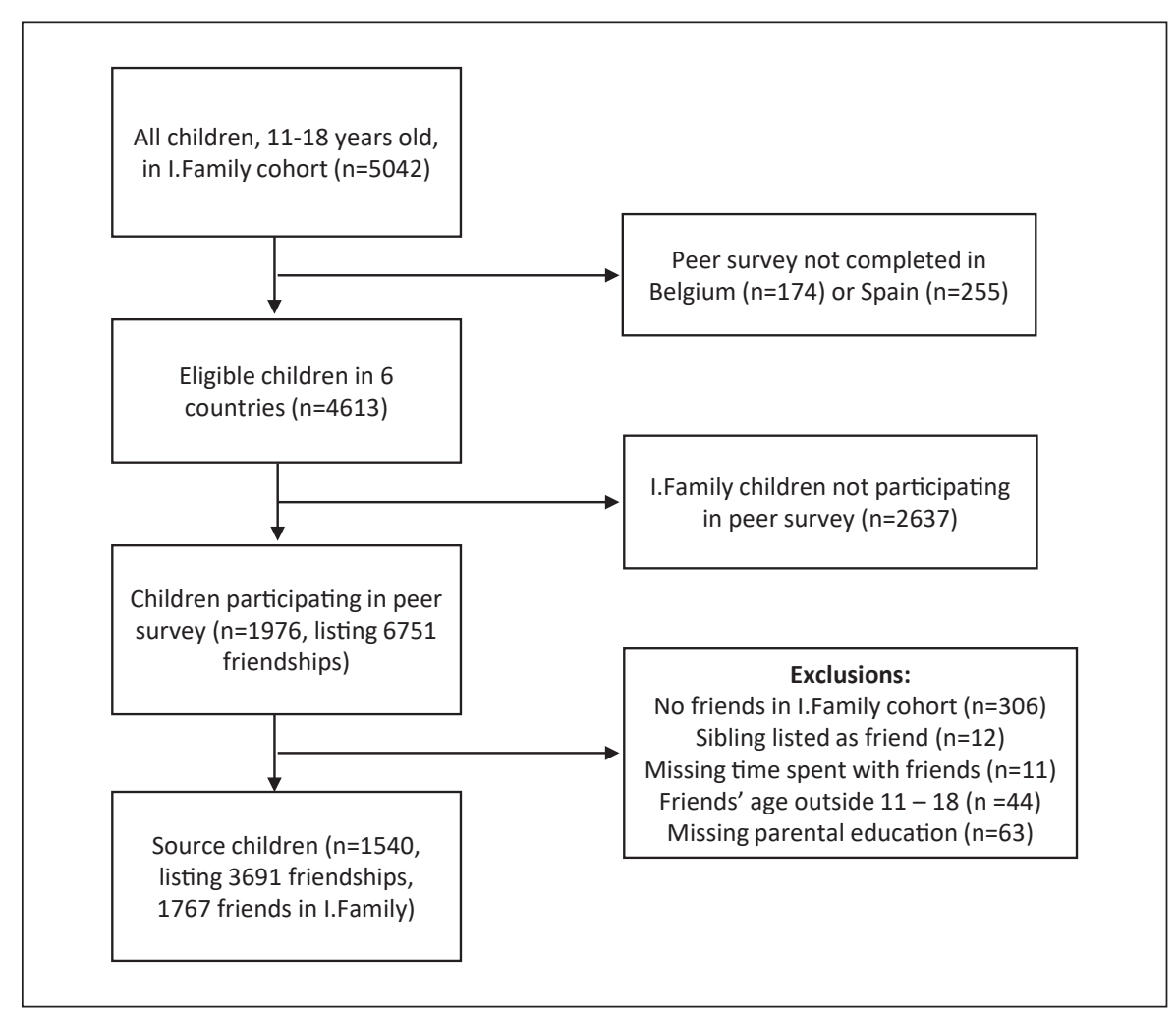

identified based on a self-administered questionnaire in which adolescents provided the names and school classes of up to 10 friends, all within the age range of 11-18 years. Those who completed this peer survey are henceforth called "source children," while the named children are called "friends." Time spent with friends, ranked on a scale from "some time (meeting occasionally)" to "a lot of time (being together often)" (range 1-5), served as an indicator for the closeness of the friendship.

Figure 1 shows the construction of the analytic sample for the present analysis including attrition and exclusions. Due to limited resources, it was not possible for research centers in Spain and Belgium to participate in this supplementary survey. Among 4,613 eligible adolescents in the remaining 6 countries, 1,976 participated in the peer survey (43\%). Because the aim was to compare standardized characteristics of source children and their friends, the latter had to be participants in the I.Family study. The lack of reported adolescent friends within the I.Family study was the main reason for exclusion of source children $(n=350$; Fig. 1$)$. The final sample was limited to 1,540 source children with information on parental education and included 1,767 friends. Because 1,161 friends were also source children, the analytic sample included data from 2,146 individual adolescents.

\section{Assessment of Covariates}

Two indicators reflecting body size were considered in this study: BMI and body fat percent. Trained field staff measured the participants' height and weight. BMI $z$-scores were calculated based on the International Obesity Task Force (IOTF) growth standards and obesity was defined according to published cut-offs [17]. Body fat percent was determined using leg-to-leg bioelectri- cal impedance analysis (TANITA BC 418 MA) and converted into $z$-scores [18]. Parental education was classified based on the International Standard Classification of Education (ISCED) [19] and dichotomized at medium level (post-secondary versus less education), using the maximum educational level of both parents. Immigrant background was based on the parents' self-reports, distinguishing at least 1 parent with an immigrant background versus neither. Psychological and lifestyle variables were based on a questionnaire completed by the adolescents themselves [18]. General well-being was assessed by 4 dimensions of the self-report versions of the KINDL-R health-related quality-of-life (HRQoL) questionnaire ( 4 items per dimension: emotional well-being, Cronbach's a 0.56; self-esteem, Cronbach's a 0.72 ; family relations, Cronbach's a 0.71 ; peer relations, Cronbach's a 0.54 ), with a range of $12-48$ and higher values indicating better well-being [20]. School-related questions were taken from the self-report version of KIDSCREEN-52 [21] describing cognitive and school functioning (6 items, Cronbach's a 0.82), as well as experiencing bullying and social rejection ( 3 items, Cronbach's a 0.77). Each item was measured on a scale from never to always, and the mean value of items was calculated for both set of questions (range 0-4). Weight concerns were measured on a scale of $0-6$ based on questions from the Eating Disorders Diagnostic Scale (4 items, Cronbach's a 0.91) [22]. Impulsive behavior was measured by 12 questions describing the adolescent's tendency to rash action, based on an abridged version of the UPPS-P (Cronbach's a 0.85) [23]. The answers were combined into a score (range 12-48) with higher values indicating higher impulsivity. Assessment of dietary behavior included a food frequency questionnaire (FFQ) based on which a variable measuring the weekly frequency of fast-food consumption was calculated. 
We also calculated propensities to consume foods rich in sugar or in fat by dividing the weekly frequency of those foods by the total frequency of all foods assessed, reflecting the relative sugar and fat intake [24]. Individual items of the FFQ showed significant reproducibility, with an average correlation of 0.59 between examinations on average half a year apart [25], and good correlation with results from a 24-h dietary recall [26] and urine biomarkers [27, 28]. Leisure time physical activity was measured in terms of the weekly number of hours spent in a sports club. Screen time was assessed as the weekly number of hours spent with audiovisual media. Comprehensive information on these methods is published elsewhere [18].

\section{Statistical Methods}

Descriptive statistics were calculated for the entire sample, and by parental education and parental immigrant background. Comparisons by parental education and by immigrant background were performed using regression models adjusted for age, sex, and country. The total number of friends was modelled using ordinal logistic regression after testing the proportional-odds assumption. To characterize the resemblance between source children and their friends, each source child's characteristic was regressed on the friends' mean values of that characteristic. Mean values for the friends' characteristics were weighted with the time spent together to account for the closeness of a friendship. The use of weighted mean values rather than properties of individual friends ascertained that observations from reciprocal friends were not replicates of each other. For continuous variables, we used linear regression to relate the friends' means to the source child's characteristics. For weight concerns, sports club hours, and screen time, we used quantile regression of the median, because the corresponding distributions showed large skewness and an excess of zeros, which precluded logarithmic transformation. The Markov chain marginal bootstrap was used to calculate $95 \%$ CIs, as implemented in the SAS procedure QUANTREG. Because continuous characteristics were measured on different scales, both the source child's and the friends' mean characteristics were standardized ( mean $=0, \mathrm{SD}=1$ ) for use in regression models, which estimate standardized beta-coefficients (denoted as $b$ ) that allow to compare the strength of associations across different characteristics [29]. The distribution for bullying and social rejection showed few distinct levels and was dichotomized into any experience of this kind versus none (henceforth: "being bullied"). Binary outcomes, that is, being bullied, parental education, and immigrant background, were analyzed using logistic regression. All regression models were adjusted for age, sex, and parental education of the source child, as well as survey country and total time spent with friends. To examine moderation by parental education, immigrant background, country, age (dichotomized at a median value of 13.5 years), or sex of the source child, we included the product between the friends' characteristics and the moderator into the model. Results were presented as stratum-specific estimates with $p$ values for interaction. Country-specific associations are shown in online supplementary Figure S2 (for all online suppl. material, see www. karger.com/doi/10.1159/000512356), including the $p$ value for an overall $F$-test for between-country differences. Goodness-of-fit was assessed using the coefficient of determination for linear regression $\left(R^{2}\right)$, the $R 1$ statistics for quantile regression [30], and the area under the receiver operating characteristic curve (AUROC) for logistic regression. Sensitivity analyses for friends' clustering on parental education and immigrant background included further adjustment on the corresponding mean values obtained from all adolescents in each municipality within a survey country. Analyses were performed using SAS (version 9.4; SAS Institute, Cary, NC, USA), and MATLAB (R2016b; MathWorks Inc.). Statistical significance was set at 0.05 (2-sided tests). The Bonferroni correction was applied to adjust for multiple comparisons.

\section{Results}

\section{Basic Characteristics}

Table 1 shows the basic characteristics of the source children. On average, these adolescents named between 2 and 3 friends who also participated in the I.Family study (range 1-9). There were large differences in $z$-scores of BMI and body fat percent, in relation to parental education ( $p<0.001$ for both obesity measures) and immigrant background ( $p=0.01$ and 0.004 , respectively). The prevalence of obesity differed by parental education ( 5 vs. $12 \%$, high vs. low) and by immigrant background (11 vs. $8 \%$, yes vs. no). Indicators of mental health and well-being did not differ by socioeconomic factors, but higher sugar propensity and screen time were associated with less parental education $(p<0.0001)$. Similar patterns were seen for traits and behaviors of friends (online suppl. Table S1). Only $7 \%$ of the source children named a friend of opposite sex (not shown). Country-specific results are shown in the online supplementary material. There were large country differences in weight-related traits and behaviors (online suppl. Fig. S1; Table S3) and in parental and friend-related variables (online suppl. Table S2). High parental education was common in Sweden (78\%) and Estonia (65\%), and least common in the Italian survey sample $(17 \%)$. The proportion of families with an immigrant background varied from $4 \%$ in Hungary to $32 \%$ in the German survey sample. Adolescents in Italy and Estonia named 3 friends on average, while $<2$ were named in Germany and Cyprus, and this pattern was also seen for time spent together with friends.

\section{Section 1: Source Children's Associations with Their Friends}

Table 2 shows the associations between source children's and their friends' BMI, body fat percent, and 10 selected weight-related traits and behaviors. After adjustment for age, sex, country, and parental education, the majority of the characteristics were significantly associated among friends. Body fat percent showed somewhat stronger associations with friends' characteristics than BMI. Ranked according to decreasing size of estimated 
Table 1. Characteristics of source children, overall and by categories of parental education, and parental immigrant background

\begin{tabular}{|c|c|c|c|c|c|c|}
\hline & & \multirow[t]{2}{*}{ Overall } & \multicolumn{2}{|c|}{ Parental education } & \multicolumn{2}{|c|}{ Immigrant background } \\
\hline & & & $\begin{array}{l}\text { high } \\
(n=712)\end{array}$ & $\begin{array}{l}\text { medium-low } \\
(n=828)\end{array}$ & $\begin{array}{l}\text { yes } \\
(n=234)\end{array}$ & $\begin{array}{l}\text { no } \\
(n=1,248)\end{array}$ \\
\hline & $n$ & mean $(\mathrm{SD})$ & mean (SD) & mean $(\mathrm{SD})$ & mean (SD) & mean $(\mathrm{SD})$ \\
\hline Age, years & 1,540 & $13.4(0.8)$ & $13.5(0.8)$ & $13.4(0.8)$ & $13.3(0.7)$ & $13.4(0.8)$ \\
\hline Number of friends & 1,540 & $2.4(1.6)$ & $2.2(1.5)$ & $2.6(1.7)$ & $2.5(1.9)$ & $2.4(1.6)$ \\
\hline Total time spent with friends ${ }^{a}$ & 1,540 & $8.8(6.6)$ & $8.1(6.2)$ & $9.4(6.9)$ & $9.2(7.5)$ & $8.9(6.5)$ \\
\hline BMI $z$-score & 1,539 & $0.67(1.11)$ & $0.43(1.07)$ & $0.87(1.10)$ & $0.86(1.12)$ & $0.63(1.11)$ \\
\hline Body fat percent $z$-score & 1,529 & $0.53(1.09)$ & $0.27(1.05)$ & $0.74(1.07)$ & $0.73(1.05)$ & $0.48(1.09)$ \\
\hline Impulsivity & 1,333 & $25.2(7.5)$ & $24.2(7.0)$ & $26.0(7.8)$ & $25.0(7.6)$ & $25.2(7.4)$ \\
\hline HRQoL & 1,370 & $38.4(5.2)$ & $38.1(5.1)$ & $38.6(5.4)$ & $39.0(4.5)$ & $38.3(5.3)$ \\
\hline Cognitive and school functioning & 1,474 & $2.57(0.69)$ & $2.59(0.67)$ & $2.56(0.71)$ & $2.69(0.66)$ & $2.55(0.69)$ \\
\hline Weight concerns & 1,441 & $1.42(1.60)$ & $1.36(1.58)$ & $1.46(1.62)$ & $1.48(1.60)$ & $1.41(1.61)$ \\
\hline Fast-food frequency, times/week & 1,457 & $3.8(2.3)$ & $3.5(2.1)$ & $4.0(2.4)$ & $3.7(2.3)$ & $3.8(2.3)$ \\
\hline Sugar propensity, $\%$ & 1,454 & $23.2(10.3)$ & $21.7(9.6)$ & $24.4(10.7)$ & $23.1(9.6)$ & $23.1(10.4)$ \\
\hline Fat propensity, $\%$ & 1,454 & $24.5(9.1)$ & $24.0(8.5)$ & $25.0(9.6)$ & $24.5(9.2)$ & $24.5(9.2)$ \\
\hline Sports club participation, h/week & 1,449 & $2.5(3.1)$ & $3.0(3.2)$ & $2.1(2.9)$ & $2.2(3.3)$ & $2.6(3.1)$ \\
\hline \multirow[t]{2}{*}{ Screen time, h/week } & 1,408 & $19.6(11.9)$ & $18.6(11.5)$ & $20.4(12.3)$ & $18.9(11.2)$ & $19.6(12.0)$ \\
\hline & $n$ & $n(\%)$ & $n(\%)$ & $n(\%)$ & $n(\%)$ & $n(\%)$ \\
\hline Male sex & 1,540 & $705(46)$ & $319(45)$ & $386(47)$ & $104(44)$ & $573(46)$ \\
\hline Being bullied ${ }^{\mathrm{b}}$ & 1,472 & $535(36)$ & $258(39)$ & $277(35)$ & $77(34)$ & $440(37)$ \\
\hline High parental education & 1,540 & $712(46)$ & - & - & $91(39)$ & $595(48)$ \\
\hline Parental immigrant background & 1,482 & $234(16)$ & $91(13)$ & $143(18)$ & - & - \\
\hline
\end{tabular}

HRQoL, health-related quality-of-life.

a For each friend: 1 = little time, $5=$ a lot of time, then summed over all friends.

${ }^{\mathrm{b}}$ Any bullying and social rejection vs. none.

standardized beta-coefficients associations with friends' mean values were largest for sports club participation followed by cognitive and school functioning, a preference for sugar-sweetened foods, screen time, impulsivity, fastfood consumption, and body fat percent. The goodnessof-fit test indicated that only up to $15 \%$ of the variation in the source child's characteristics was explained by the respective model. Bullying experienced by friends was associated with almost $80 \%$ higher odds of the source child being bullied, too. This association was independent of the source child's BMI (not shown). Source children's HRQoL was not associated with their friends HRQoL, weight concerns, or fat propensity, but time spent with friends was positively associated with better HRQoL (not shown). Conclusions about between-friend associations regarding 10 weight-related traits and behaviors were not affected by Bonferroni correction for multiple testing.
Section 2: Moderation of Friendship Associations by Sociodemographic Factors and Survey Country

The results from interaction analyses by parental education and immigrant background are detailed in Table 3. Stratum-specific estimates showed that associations with friends' BMI and body fat percent could only be detected in source children with highly educated parents. In contrast, no effect modifications by immigrant background were seen for body size measures. Correlations between weight-related traits and behaviors did not differ by parental education. Differences by parental immigrant background were observed for school functioning and sugar propensity, but these were not significant after Bonferroni correction for multiple testing. Associations between source children's and friends' properties did not differ by sex or age (dichotomized at a median value of 13.5 years) of the source child except for larger associations in screen time among boys, $b=0.20(0.10-0.30)$, 
Table 2. Associations between source children's and friends' characteristics

\begin{tabular}{|c|c|c|}
\hline & Estimates & Goodness-of-fit ${ }^{\mathrm{c}}$ \\
\hline \multicolumn{3}{|c|}{ Body size measures, standardized $\beta$-coefficient (95\% CI) } \\
\hline BMI $z$-score & $0.04(-0.01$ to 0.09$)$ & 0.12 \\
\hline Body fat percent $z$-score & $0.08(0.02 \text { to } 0.13)^{* *}$ & 0.15 \\
\hline \multicolumn{3}{|c|}{ Body size-related traits, standardized $\beta$-coefficient (95\% CI) } \\
\hline Impulsivity & $0.10(0.04 \text { to } 0.16)^{* * *}$ & 0.06 \\
\hline HRQoL & $0.04(-0.15$ to 0.10$)$ & 0.06 \\
\hline Cognitive and school functioning & $0.13(0.08 \text { to } 0.18)^{* * *}$ & 0.11 \\
\hline Weight concerns ${ }^{\mathrm{a}}$ & $0.01(-0.04$ to 0.06$)$ & 0.12 \\
\hline Fast food consumption, times/week & $0.08(0.03 \text { to } 0.14)^{* *}$ & 0.15 \\
\hline Sugar propensity, $\%$ & $0.12(0.07 \text { to } 0.17)^{* * *}$ & 0.08 \\
\hline Fat propensity, $\%$ & $0.03(-0.02$ to 0.08$)$ & 0.03 \\
\hline Sports club participation, $\mathrm{h} /$ week $^{\mathrm{a}}$ & $0.22(0.17 \text { to } 0.28)^{* * *}$ & 0.15 \\
\hline Screen time, $\mathrm{h} /$ week $^{\mathrm{a}}$ & $0.11(0.06 \text { to } 0.17)^{* * *}$ & 0.11 \\
\hline Being bullied ${ }^{\mathrm{b}}, \mathrm{OR}$ (95\% CI) & $1.24(1.11 \text { to } 1.38)^{* * *}$ & 0.60 \\
\hline
\end{tabular}

Associations between the source child's characteristics and mean value of friends' characteristics weighted by the time spent together, adjusted for age, sex, country, and parental education. ${ }^{* *} p<0.01,{ }^{* * *} p<0.001$. HRQoL, health-related quality-of-life.

${ }^{\mathrm{a}}$ Quantile regression.

${ }^{\mathrm{b}}$ Logistic regression, OR for being bullied per SD change in friends' percentage of being bullied (SD 38.4\%).

${ }^{\mathrm{c}} R^{2}$ (linear regression), $R 1$ (quantile regression), AUROC (logistic regression).

compared to girls, $b=0.03(-0.05$ to 0.11 ; interaction $p$ value $=0.008)$. Despite country differences in absolute values for weight-related traits (online suppl. Fig. S1; Table S3), the associations between source children and their friends were generally consistent across countries (online suppl. Fig. S2; Table S3), with minor exceptions for fast-food consumption and fat propensity. Sports club participation, screen time, and being bullied were traits that consistently showed positive associations between source children and friends in all 6 countries (last row in online suppl. Fig. S2).

\section{Section 3: Friendship Associations in Parental} Education and Immigrant Background

In view of the sociodemographic moderation of correlations regarding body size indicators, we also investigated associations between source children and friends in sociodemographic variables themselves. Although parental education and immigrant background differed across countries (online suppl. Table S2), we found consistent positive associations between the source child's high parental education and the percentage of friends with high parental education in all countries except Sweden (Table 4). An interaction between friends' parental education and survey country indicated large country dif- ferences in the associations with friends, which was attributable to Sweden being in the analysis (no interaction was observed after exclusion of the Swedish sample). A similar pattern was observed for immigrant background, although the interaction by country was not significant. For this analysis, observations from the Hungarian sample were excluded because of a low prevalence of parental immigrant background (online suppl. Table S2). We note that parental education was not associated with immigrant background, assuring that both variables measure different sociodemographic aspects (not shown). Further adjustment for mean values of parental education or immigrant background calculated from all peers in the same municipality as the source child did not change the results given in Table 4 (not shown). This result confirms that these associations are due to properties shared with specific friends rather than with unrelated peers living in the same neighborhood.

\section{Discussion}

This study aimed to characterize adolescent friendship similarities in relation to weight status and weight-related traits and behaviors, with focus on the impact of the 


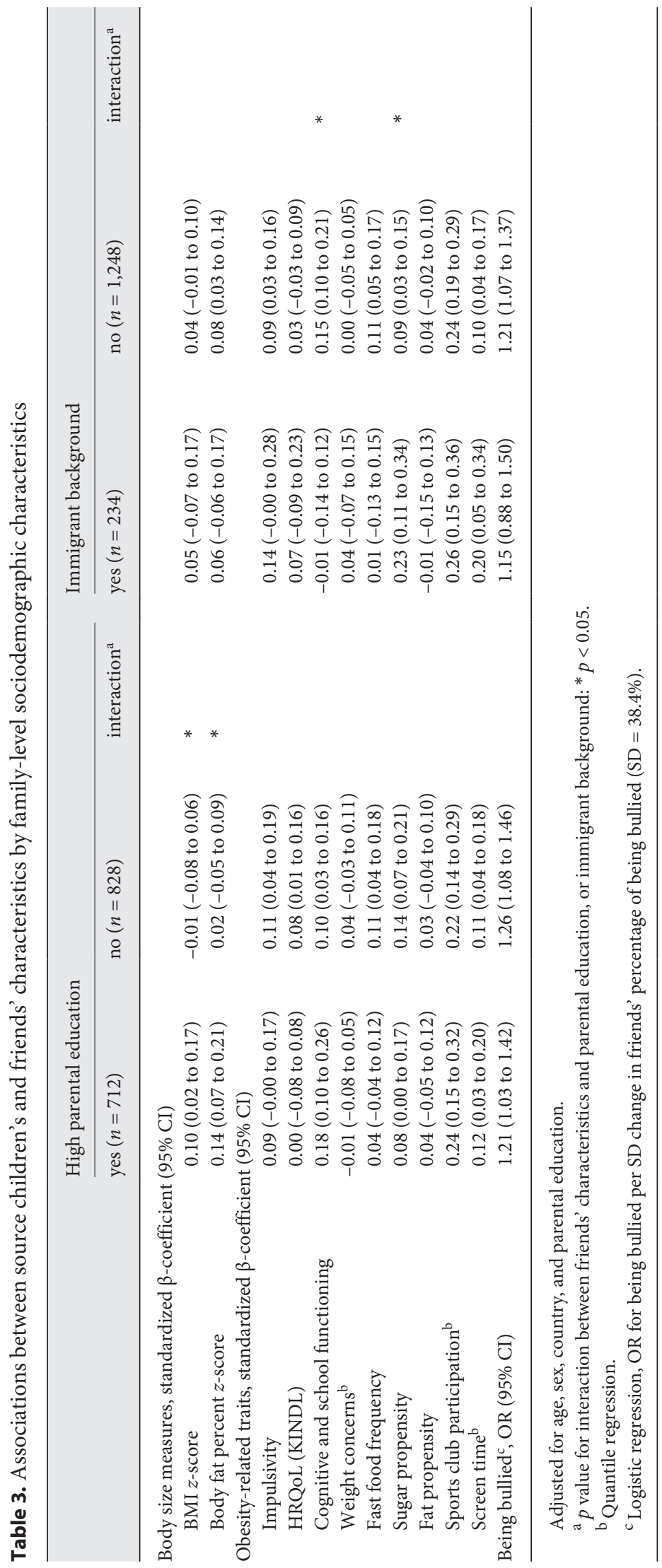

Friendship Similarities in Weight-Related Traits among European Adolescents broader social environment. For weight measures, there were positive associations between source children's and their friends' body fat percent $z$-score but not for BMI $z$ scores. Regarding weight-related behaviors, adolescents showed positive associations with their friends' characteristics regarding the frequency of fast-food consumption, screen time, preference for sugar-sweetened foods, and hours spent in sports clubs, in increasing order of importance. No associations with friends were seen for a preference for high-fat foods, or for HRQoL and weight concerns, but impulsivity, cognitive and school functioning, and being bullied were strongly associated between friends. Furthermore, we detected an effect modification by parental education showing friendship associations in $\mathrm{BMI}$ and in body fat percent $z$-scores among source children with high parental education only, but no modification by parental education was observed for any of the other traits and behaviors. With few exceptions, friendship associations did not differ by immigrant background or country. No effect modifications by age class or sex of the source child were observed, except for associations regarding screen time that were stronger among boys than girls. Lastly, we found that friendships generally tended to cluster positively on parental education and on immigrant background in all countries except Sweden.

Overall, our results support previous findings on adolescent friend similarities regarding measures of body weight $[3,11,31]$, but the restriction to adolescents with high parental education adds a new dimension to this phenomenon. Previous analyses in a subsample of the present cohort were not able to highlight this issue due to a disproportionate selection of participants with highly educated parents [32]. It can be hypothesized that better health literacy and higher parental demands influence the adolescent's choice of friends with a similar weight status. In contrast, no differences by parental education were seen for weight-related traits and behaviors. A potential explanation might be that the latter were self-reported, and more variable than objectively measured weight variables that can be assumed to be more stable over time. In addition, the results may indirectly indicate the lack of important determinants of body weight such as genetics and family history of overweight and obesity, which may display stronger socioeconomic differences than the ten weight-related traits and behaviors examined in this study [33]. Our findings that friends are similar in impulsivity as well as fast-food consumption and sugar preference may be consistent with a predisposition to weight problems [34, 35]. The associations regarding sugar preference were more evident in children with a parental im- 
Table 4. Country-specific associations between source children and friends in family-level sociodemographic characteristics

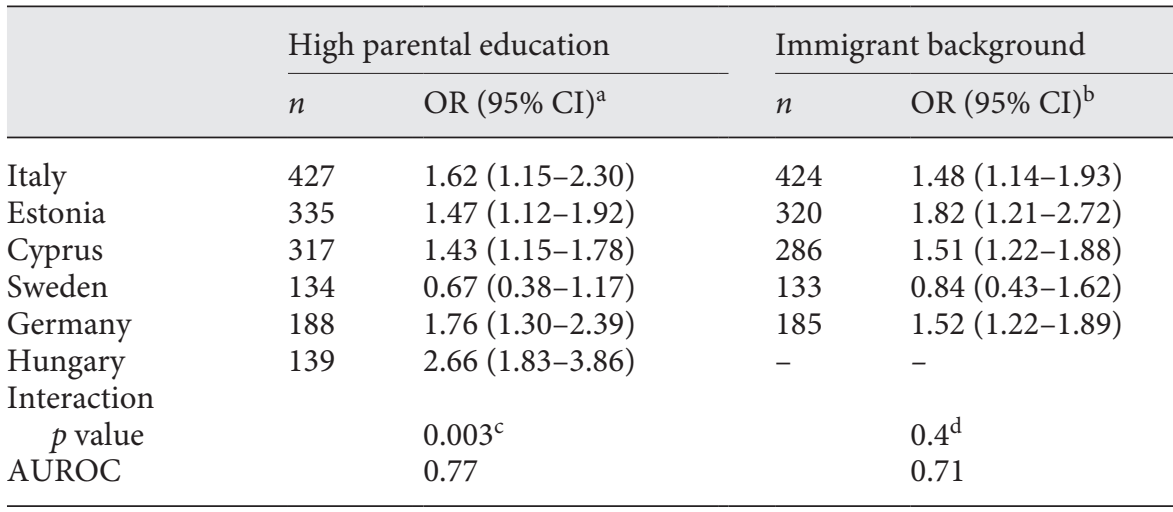

Logistic regression adjusted for age, sex, total time spent with friends, and including interactions between country and parental education, and immigrant status, respectively.

a Odds ratio for source children's high parental education per SD of percentage of friends with high parental education (SD $=43.7 \%)$.

${ }^{\mathrm{b}}$ Odds ratio for parental immigrant background per SD of percentage of friends with parental immigrant background $(\mathrm{SD}=28.6 \%)$.

${ }^{\mathrm{c}}$ Wald $\chi^{2}$ test statistics $=18.2, \mathrm{df}=5$.

${ }^{\mathrm{d}}$ Wald $\chi^{2}$ test statistics $=3.87, \mathrm{df}=4$. migrant background, indicating a higher vulnerability in this subgroup. School-related well-being, defined in terms of problems and success, are properties that correlated strongly between source children and friends. Associations observed for being bullied suggest that adolescents share properties that increase their likelihood for being bullied, such as obesity, but contrary to our expectation friends' associations in being bullied was not explained by weight status. Furthermore, screen time behavior was associated among friends, with a larger effect size in boys compared to girls; otherwise, the lack of sex differences is consistent with other research [6]. A strong association among friends was seen regarding sports club participation that was remarkably independent of social factors, despite social gradients in absolute values of sports club participation. These results are consistent with earlier work showing that positive friendship relationships fostered involvement in physical activity $[3,6$, 36-38]. Taken together with associations regarding being bullied, these results underline the significance of shared activities among adolescents, and shared leisure time physical activity may be an important example.

The clustering of friends on parental education and on immigrant background independent of properties in their local neighborhood confirms that this type of social homophily [9] is already occurring in adolescence [12]. The exception of Sweden may be suggestive of societal differences that play a role. Considering all the countries in the study, Sweden may be relatively egalitarian as suggested by, for instance, the lowest Gini coefficient of income inequality among citizens [39]. A concrete example is the documented commitment of Swedish governments to reduce segregation by mixing affluent and less affluent housing facilities, which may enhance the probability of youths of different backgrounds befriending each other [40]. Our findings support the idea that interventions reducing social barriers, in particular among children and adolescents, may be a promising strategy to improve the health status in the population. However, the Swedish sample was small and friendship associations showed large variation, which may not allow us to draw conclusions about the absence of inequalities.

This study offers an enhanced understanding of similarities between adolescent friends in relation to their socioeconomic background, which has previously been scarce in the literature [11]. In-depth phenotyping allowed analyses of weight status and body composition as well as 12 weight-related indicators including sociodemographic characteristics. Another strength of the current study was the participation of 6 distinctly different countries, contributing to diversity in terms of sociodemographic characteristics of adolescents. However, the country-based data may be both a strength and a weakness. Results stratified on the basis of the 6 survey samples cannot be generalized to national levels, and country-specific findings must be considered with caution. The re- 
striction to friends from the I.Family study may underestimate the true associations if influential friends are not included. The implicit restriction to school friends may also produce an overestimation if schoolmates are more similar than friends from other social environments. However, we find associations regarding both school-related aspects and school-independent variables, such as being bullied and sports club participation, respectively. Due to the cross-sectional nature of this study we could only assess associations between friends, and not distinguish between the situations where friends affect the source child's behavior, and where children make friends because they already share certain properties.

\section{Conclusions}

Adolescent friends shared several weight-related characteristics. BMI and body fatness appeared to have a socioeconomic component, in which between-friend associations were stronger in adolescents with high parental education. A number of other traits were correlated among friends, the strongest being sports club participation, screen time, and being bullied. Correlations regarding these traits did not vary by parental education. Moreover, family-level sociodemographic characteristics themselves tended to be similar among friends. Specifically, adolescent friends clustered by parental education and non-native background in most survey countries. These results confirm that aggregation by social as well as weight-related factors is already occurring in adolescence, highlighting the importance to direct health promotion initiatives in adolescents towards peer groups in both school-related and leisure-time environments. The similarities among adolescent friends may be a foreshadowing of social inequalities in future relationships [4143].

\section{References}

1 Christakis NA, Fowler JH. The spread of obesity in a large social network over 32 years. $\mathrm{N}$ Engl J Med. 2007 Jul;357(4):370-9.

2 Barabási AL. Network medicine-from obesity to the "diseasome". N Engl J Med. 2007 Jul; 357(4):404-7.

Friendship Similarities in Weight-Related Traits among European Adolescents

\section{Acknowledgements}

We thank the children and parents who participated in the examinations of the IDEFICS-I.Family cohort study.

\section{Statement of Ethics}

This study was conducted according to the guidelines of the Declaration of Helsinki, and all procedures involving human subjects were approved by the responsible local or national Ethics Committees for each of the study centers conducting the fieldwork. Parents and adolescents gave written informed consent for all examinations as well as for the collection and storage of personal data. They could consent to single components of the study while refraining from others.

\section{Conflict of Interest Statement}

The authors have no conflicts of interest to declare.

\section{Funding Sources}

This work was conducted as part of the IDEFICS (http://www. idefics.eu) and I.Family studies (http://www.ifamilystudy.eu/). The authors gratefully acknowledge the financial support of the European Commission within the Sixth RTD Framework Program Contract No. 016181 (FOOD), and the Seventh RTD Framework Program Contract No. 266044, and funding within the EpiLife research program (Swedish Research Council for Working Life and Social Research; grant No. 2006-1506), Swedish Research Council for Environment, Agricultural Sciences, and Spatial Planning (grant No. 2012-00038), and Swedish Research Council (grant No. 2015-02508).

\section{Author Contributions}

L.L., E.E., C.Ha., J.K., F.L., N.M., I.P., L.A.R., and T.V. represent the consortium that initiated the IDEFICS/I.Family study and collected the data. L.L., K.M., C.Ho., L.H.B., A.H., and J.K. developed the research question and the design for this project. K.M. performed the statistical analyses and wrote the first draft of the manuscript. All authors read, commented on, and approved the final manuscript.
3 Ali MM, Amialchuk A, Heiland FW. Weightrelated behavior among adolescents: the role of peer effects. PLoS One. 2011;6(6):e21179.

4 Fletcher A, Bonell C, Sorhaindo A. You are what your friends eat: systematic review of social network analyses of young people's eating behaviours and bodyweight. J Epidemiol Community Health. 2011 Jun;65(6):548-55.
5 Salvy SJ, de la Haye K, Bowker JC, Hermans RC. Influence of peers and friends on children's and adolescents' eating and activity behaviors. Physiol Behav. 2012 Jun;106(3):36978 . 
6 Daw J, Margolis R, Verdery AM. Siblings, friends, course-mates, club-mates: how adolescent health behavior homophily varies by race, class, gender, and health status. Soc Sci Med. 2015 Jan;125:32-9.

7 Chung SJ, Ersig AL, McCarthy AM. The Influence of Peers on Diet and Exercise Among Adolescents: A Systematic Review. J Pediatr Nurs. 2017 Sep - Oct;36:44-56.

8 Bogl LH, Mehlig K, Ahrens W, Gwozdz W, de Henauw S, Molnár D, et al.; IDEFICS and I. Family Consortia. Like me, like you - relative importance of peers and siblings on children's fast food consumption and screen time but not sports club participation depends on age. Int J Behav Nutr Phys Act. 2020 Apr;17(1):50.

9 McPherson M, Smith-Lovin L, Cook JM. Birds of a Feather: Homophily in Social Networks. Annu Rev Sociol. 2001;27(1):415-44.

10 Cohen-Cole E, Fletcher JM. Detecting implausible social network effects in acne, height, and headaches: longitudinal analysis. BMJ. 2008 Dec;337:a2533.

11 Mora T, Gil J. Peer effects in adolescent BMI: evidence from Spain. Health Econ. 2013 May; 22(5):501-16.

12 Schachner MK, Van de Vijver FJ. Alaina, Noack P. Who is friends with whom? Patterns of inter- and intraethnic friendships of mainstream and immigrant early adolescents in Germany. Reims: International Association for CrossCultural Psychology Conferences; 2016.

13 Rostila M. Birds of a feather flock togetherand fall ill? Migrant homophily and health in Sweden. Sociol Health Illn. 2010 Mar;32(3): 382-99.

14 Ahrens W, Siani A, Adan R, De Henauw S, Eiben G, Gwozdz W, et al.; I.Family consortium. Cohort Profile: the transition from childhood to adolescence in European children-how I.Family extends the IDEFICS cohort. Int J Epidemiol. 2017 Oct;46(5):13941395j.

15 Ahrens W, Bammann K, Siani A, Buchecker K, De Henauw S, Iacoviello L, et al.; IDEFICS Consortium. The IDEFICS cohort: design, characteristics and participation in the baseline survey. Int J Obes. 2011 Apr;35(Suppl 1):S3-15.

16 Ahrens W, Bammann K, de Henauw S, Halford J, Palou A, Pigeot I, et al.; European Consortium of the IDEFICS Project. Understanding and preventing childhood obesity and related disorders-IDEFICS: a European multilevel epidemiological approach. Nutr Metab Cardiovasc Dis. 2006 May;16(4):302-8.

17 Cole TJ, Lobstein T. Extended international (IOTF) body mass index cut-offs for thinness, overweight and obesity. Pediatr Obes. 2012 Aug;7(4):284-94.
18 Bammann K, Lissner L, Pigeot I, Ahrens W, editors. Instruments for health surveys in children and adolescents. Cham: Springer Nature Switzerland; 2019. pp. 189-207.

19 UNESCO. International Standard Classification of Education ISCED 2011, UIS/2012/ INS/10/REV. Institute of Statistics; 2012.

20 Ravens-Sieberer U, Bullinger M. Assessing health-related quality of life in chronically ill children with the German KINDL: first psychometric and content analytical results. Qual Life Res. 1998 Jul;7(5):399-407.

21 Robitail S, Simeoni MC, Erhart M, RavensSieberer U, Bruil J, Auquier P; European Kidscreen Group. Validation of the European proxy KIDSCREEN-52 pilot test health-related quality of life questionnaire: first results. J Adolesc Health. 2006 Oct;39(4):596.e1-10.

22 Stice E, Telch CF, Rizvi SL. Development and validation of the Eating Disorder Diagnostic Scale: a brief self-report measure of anorexia, bulimia, and binge-eating disorder. Psychol Assess. 2000 Jun;12(2):123-31.

23 Whiteside SP, Lynam DR, Miller JD, Reynolds SK. Validation of the UPPS impulsive behaviour scale: a four-factor model of impulsivity. Eur J Pers. 2005;19(7):559-74.

24 Lanfer A, Knof K, Barba G, Veidebaum T, Papoutsou S, de Henauw S, et al. Taste preferences in association with dietary habits and weight status in European children: results from the IDEFICS study. Int J Obes. 2012 Jan; 36(1):27-34.

25 Lanfer A, Hebestreit A, Ahrens W, Krogh V, Sieri S, Lissner L, et al.; IDEFICS Consortium. Reproducibility of food consumption frequencies derived from the Children's Eating Habits Questionnaire used in the IDEFICS study. Int J Obes. 2011 Apr;35(Suppl 1):S61-

26 Lissner L, Lanfer A, Gwozdz W, Olafsdottir S, Eiben G, Moreno LA, et al. Television habits in relation to overweight, diet and taste preferences in European children: the IDEFICS study. Eur J Epidemiol. 2012 Sep;27(9):70515.

27 Huybrechts I, Börnhorst C, Pala V, Moreno LA, Barba G, Lissner L, et al.; IDEFICS Consortium. Evaluation of the Children's Eating Habits Questionnaire used in the IDEFICS study by relating urinary calcium and potassium to milk consumption frequencies among European children. Int J Obes. 2011 Apr; 35(Suppl 1):S69-78.

28 Intemann T, Pigeot I, De Henauw S, Eiben G, Lissner L, Krogh V, et al.; I.Family consortium. Urinary sucrose and fructose to validate self-reported sugar intake in children and adolescents: results from the I.Family study. Eur J Nutr. 2019 Apr;58(3):1247-58.

29 Freund RJ, Wilson WJ, Mohr DL. Statistical methods. 3rd ed. Amsterdam; Boston: Elsevier; 2010. xxi, $796 \mathrm{p}$.

30 Koenker R, Machado JA. Goodness of fit and related inference processes for quantile regression. J Am Stat Assoc. 1999;94(448): 1296-310.
31 Fletcher A, Bonell C, Sorhaindo A. You are what your friends eat: systematic review of social network analyses of young people's eating behaviours and bodyweight. J Epidemiol Community Health. 2011 Jun;65(6):548-55.

32 Gwozdz W, Nie P, Sousa-Poza A, DeHenauw S, Felső R, Hebestreit A, et al. Peer effects on weight status, dietary behaviour and physical activity among adolescents in Europe: findings from the I.Family Study. Kyklos. 2019; 72(2):270-96.

33 Silventoinen K, Jelenkovic A, Latvala A, Yokoyama $\mathrm{Y}$, Sund R, Sugawara M, et al. Parental education and genetics of BMI from infancy to old age: a pooled analysis of 29 twin cohorts. Obesity. 2019 May;27(5):855-65.

34 Gilman JM, Curran MT, Calderon V, Stoeckel LE, Evins AE. Impulsive social influence increases impulsive choices on a temporal discounting task in young adults. PLoS One. 2014 Jul;9(7):e101570.

35 Thamotharan S, Lange K, Zale EL, Huffhines $\mathrm{L}$, Fields $\mathrm{S}$. The role of impulsivity in pediatric obesity and weight status: a meta-analytic review. Clin Psychol Rev. 2013 Mar;33(2):25362.

36 Salvy SJ, de la Haye K, Bowker JC, Hermans RC. Influence of peers and friends on children's and adolescents' eating and activity behaviors. Physiol Behav. 2012 Jun;106(3):36978.

37 Chung SJ, Ersig AL, McCarthy AM. The influence of peers on diet and exercise among adolescents: a systematic review. J Pediatr Nurs. 2017;36:44-56

38 Salway RE, Sebire SJ, Solomon-Moore E, Thompson JL, Jago R. Associations within school-based same-sex friendship networks of children's physical activity and sedentary behaviours: a cross-sectional social network analysis. Int J Behav Nutr Phys Act. 2018 Feb; 15(1): 18

39 World Bank GINI index. Available from: https://dataworldbankorg/indicator/SIPOVGINI/ (accessed July 2, 2019).

40 OXFAM. The commitment to reducing inequality index. Oxfam International and Development Finance International. 2017.

41 Reynolds CA, Baker LA, Pedersen NL. Multivariate models of mixed assortment: phenotypic assortment and social homogamy for education and fluid ability. Behav Genet. 2000 Nov;30(6):455-76.

42 Silventoinen K, Kaprio J, Lahelma E, Viken RJ, Rose RJ. Assortative mating by body height and BMI: finnish twins and their spouses. Am J Hum Biol. 2003 Sep-Oct;15(5): 620-7.

43 van der Zee MD, Helmer Q, Boomsma DI, Dolan CV, de Geus EJ. An extended twinpedigree study of different classes of voluntary exercise behavior. Behav Genet. 2020 Mar;50(2):94-104 